\title{
Estudo Comparativo entre as Novas Ferramentas Digitais Utilizadas no Desenho à Mão Livre
}

\author{
Comparative Study between the New Digital Tools Used in Freehand Drawings
}

\author{
Renato Tamaoki Figueiredo \\ Universidade de São Paulo, Brasil \\ tamaoki.r@gmail.com \\ Simone Helena Tanoue Vizioli \\ Universidade de São Paulo, Brasil \\ simonehtv@sc.usp.br
}

\begin{abstract}
This paper makes an analysis on the new technological resources related to architectural drawing that make use of the hand drawing. It tests and evaluates the use of new tools such as tablets (e.g. Wacom Bamboo), graphic tablets (e.g. iPad), tablet/screen hybrids (e.g. Wacom Cintiq) and electronic pens (e.g. Wacom Inkling) in the making of free drawings oriented for the developing of graphic products related to the projective act in architecture and design. The paper makes a comparative e interpretative analysis through the reading of those products.
\end{abstract}

Keywords: Digital drawing; Freehand drawing; Project process; Design.

\section{Introducão}

Esta pesquisa insere-se nas atividades desenvolvidas no Núcleo de Apoio à Pesquisa em Estudos de Linguagem em Arquitetura e Cidade. Este grupo desenvolve pesquisas de temas relacionados à Linguagem e Representação dando ênfase aos processos cognitivos presentes tanto na percepção da cidade e da arquitetura, quanto nos processos projetuais. Procura-se caracterizar as diferentes perspectivas teóricas e práticas existentes na relação dos meios de representação com o ensino de Arquitetura e Urbanismo, atentos às relações processuais e metodológicas existentes entre elas. Dessa maneira, objetiva-se destacar os vínculos entre os meios de representação, artísticos ou não, e a consciência crítica e propositiva de espacialidade, seja urbana ou arquitetônica.

A pesquisa tem como objetivo principal testar e avaliar os recursos das interfaces digitais recentes que usam o desenho à mão livre como elemento significante em seus processos, principalmente durante o processo projetivo. Para tal, foi realizado um conjunto de experimentos práticos - o projeto de uma série de luminárias com cada ferramenta elencada - a fim de avaliar e comparar qualitativamente $\mathrm{o}$ ato de projeto nessas ferramentas digitais e em seus programas e recursos.

\section{O Desenho}

O momento histórico atual é marcado pela abundância de meios de comunicação visual e da indústria do entretenimento, frutos do desenvolvimento tecnológico. Esses ingredientes marcam um horizonte norteado pela imagem, que exalta o espetáculo e o efêmero. Durante os últimos anos, vêm-se questionando veementemente os papéis das representações gráficas (CASTRAL, VIZIOLI, 2011).

Apesar de sua natureza algorítmica e pré-determinada, a tecnologia digital introduziu novas maneiras de traduzir e transformar (QUANTRILL, 2002) o processo cognitivo do sketch pela sua interação com o usuário. Recentemente, as tecnologias das tablets opacos (ex: Wacom Intuos) e gráficos (ex: Apple iPad) além de outros aparelhos tais como as canetas eletrônicas de esboço gráfico (ex:Wacom Inkling) surgiram e ofereceram novas interfaces que estreitam de maneira significativa a até então distante relação entre o computador e o humano. $O$ processo de criatividade sujeita tanto o individuo quanto a tecnologia a um desenvolvimento constante, ofertando indefinidamente novas possibilidades de expressão e representação.

Constitui-se, por meio das novas tecnologias de representação gráfica, um novo campo de estudos para a compreensão dos processos cognitivos do ato de projetar associado ao desenho livre. Constituído no processo construtivo do olhar, o ato projetual, associado à personalidade do desenho, pode, através dessas tecnologias, seguir desempenhando papel essencial no projeto arquitetônico. É pertinente que se faça uma investigação dos recursos e possibilidades que essas recentes ferramentas de interação gráfica digital apresentam, explorados por meio dos aplicativos desenvolvidos para esse fim, a fim de avaliar essas 
novas interações do usuário com o desenho livre enquanto parte constituinte do processo projetual. Mediadas pelo préestabelecimento de diversos temas e propostas que se relacionem com os processo projetuais na arquitetura e no design, optou-se por fazer uma abordagem abrangente do uso das ferramentas, dando à pesquisa o caráter de análise comparativa da atividade.

Investigando a noção de uma cultura de design arquitetônica expandida a partir da revolução digital e baseada nas categorias analíticas propostas por Villém Flusser (FLUSSER, 2008) e relacionando a concepção da imagem arquitetônica aos conceitos da obra do filósofo, Pedro Veloso (VELOSO, 2011). Veloso (VELOSO, 2011) compara os sistemas de criação produtiva, que seriam responsáveis por gerar duas posturas para o labor do arquiteto, estabelecendo novas perspectivas para o desenho arquitetônico auxiliado por computador. Em uma delas, o homem tem posição central no processo criativo predominante, autográfico e engajado, produzindo a imagem mental com o auxílio de representações manuais, estabelecendo o ciclo do projeto em torno de si. Com o uso de aparelhos eletrônicos para esse fim, esse ciclo sofre rupturas e o papel do homem é descentralizado, gerando uma segunda postura, em que a produção se torna uma simbiose de dois agentes, um pensante e outro que processa informações, colocando em pauta um novo ciclo de projeto, que coloca homem e aparelho em conflito, gerando um jogo de exploração de possibilidades, sugerindo uma soma das idiossincrasias humanas às da caixa preta autônoma, o que demanda novas formas de diálogos e interações.

A partir de experiências prévias com os aparelhos eletrônicos desenvolvidas pelo grupo de pesquisa à qual essa pesquisa se vincula (N.ELAC USP) e apoiado nas questões teóricas levantadas, compreendeu-se que um momento prévio é necessário afim de que o usuário possa conhecer seus recursos e possibilidades, antes que se possa de fato usá-lo como um recurso para o ato projetivo, além de somar a isso também um momento de produção intensa direcionada de projeto, para que se possa então obter um repertório suficiente para que o usuário não tenha problemas com o funcionamento do aparelho. De maneira mais clara, para que se faça uso de qualquer uma dessas ferramentas, dois momentos de interação são necessários: um de experiência de livre exploração do aparelho e dos programas, e o outro de experiência direcionada, com um objetivo ou produto específico a ser projetado. O primeiro referindo-se a uma etapa de experimentação livre e o outro caracterizado pelo projeto de um objeto utilizando essas ferramentas. Partindo da utilização livre dos equipamentos durante as primeiras fases do experimento, foi possível produzir uma tabela qualitativa comparativa entre eles, de maneira que se pudesse otimizar a objetividade da análise dos resultados.

\begin{tabular}{|c|c|c|c|c|c|c|c|}
\hline FERR & & PORTABILIDADE & $\begin{array}{l}\text { AMBIENTE DE } \\
\text { TRABALHO }\end{array}$ & $\begin{array}{l}\text { SOFTWARES } \\
\text { DISPONIVEIS }\end{array}$ & $\begin{array}{c}\text { INTERAÇÃO COM } \\
\text { IIMGENS } \\
\text { EXTERNAS/INTERNET }\end{array}$ & $\begin{array}{l}\text { QUALIDADES } \\
\text { GRÁFICAS }\end{array}$ & ESPECIFICIDADES \\
\hline $\begin{array}{c}\text { DESENHO } \\
\text { À MÃO }\end{array}$ & - & alta & $\begin{array}{l}\text { superfície } \\
\text { plana }\end{array}$ & - & $\begin{array}{l}\text { depende de } \\
\text { ferramentas } \\
\text { externas }\end{array}$ & $\begin{array}{l}\text { desenho a lápis, de- } \\
\text { senho a caneta, de- } \\
\text { senho aquarelado }\end{array}$ & $\begin{array}{l}\text { sensação física do } \\
\text { tato: contato entre } \\
\text { lápis e papel }\end{array}$ \\
\hline $\begin{array}{l}\text { WACOM } \\
\text { INKLING }\end{array}$ & & alta & $\begin{array}{l}\text { superfície } \\
\text { plana + acesso } \\
\text { periódico à ener- } \\
\text { gia elétrica }\end{array}$ & \begin{tabular}{|l|} 
software de interação \\
disponibilizado pela \\
produtora; exportação \\
para formato .psd
\end{tabular} & \begin{tabular}{|l|} 
digitalizado auto- \\
maticamente pelo \\
sensor do aparelho
\end{tabular} & $\begin{array}{l}\text { caneta esferográfica } \\
\text { azul }\end{array}$ & $\begin{array}{l}\text { desenho digital em } \\
\text { camadas: altera a per- } \\
\text { cepção do desenho } \\
\text { ("filmagem") }\end{array}$ \\
\hline $\begin{array}{l}\text { APPLE } \\
\text { IPAD }\end{array}$ & & alta & $\begin{array}{l}\text { acesso periódico } \\
\text { à energia elétrica }\end{array}$ & $\begin{array}{l}\text { softwares desenvolvi- } \\
\text { dos exclusivamente } \\
\text { para essa ferramenta - } \\
\text { pouco voltadas ao de- } \\
\text { senho de projeto }\end{array}$ & $\begin{array}{l}\text { acesso sem fio à } \\
\text { internet }\end{array}$ & $\begin{array}{l}\text { recursos infinitos } \\
\text { próprios aos pro- } \\
\text { gramas: linha, cor, } \\
\text { superfície }\end{array}$ & $\begin{array}{l}\text { portabilidade: fotogra- } \\
\text { fia; traço pouco preci- } \\
\text { so; pequena superfi- } \\
\text { cie de trabalho }\end{array}$ \\
\hline $\begin{array}{l}\text { WACOM } \\
\text { BAMBOO }\end{array}$ & & média & $\begin{array}{l}\text { computador + } \\
\text { acesso periódico } \\
\text { à energia elétrica }\end{array}$ & $\begin{array}{l}\text { todo e qualquer soft- } \\
\text { ware desenvolvido } \\
\text { para computador pes- } \\
\text { soal }\end{array}$ & $\begin{array}{l}\text { acesso sem fio à } \\
\text { internet por meio } \\
\text { do computador re- } \\
\text { querido pela ferra- } \\
\text { menta }\end{array}$ & $\begin{array}{l}\text { recursos infinitos } \\
\text { próprios aos pro- } \\
\text { gramas: linha, cor, } \\
\text { superficie }\end{array}$ & $\begin{array}{l}\text { desenho análogo ao } \\
\text { "desenho cego" }\end{array}$ \\
\hline $\begin{array}{l}\text { WACOM } \\
\text { CINTIQ }\end{array}$ & & baixa & $\begin{array}{l}\text { computador }+ \\
\text { acesso permanen- } \\
\text { te à energia elétri- } \\
\text { ca }\end{array}$ & $\begin{array}{l}\text { todo e qualquer soft- } \\
\text { ware desenvolvido } \\
\text { para computador pes- } \\
\text { soal }\end{array}$ & $\begin{array}{l}\text { acesso sem fio à } \\
\text { internet por meio } \\
\text { do computador re- } \\
\text { querido pela ferra- } \\
\text { menta }\end{array}$ & $\begin{array}{l}\text { recursos infinitos } \\
\text { próprios aos pro- } \\
\text { gramas: linha, cor, } \\
\text { superficie }\end{array}$ & $\begin{array}{l}\text { desenho próximo ao } \\
\text { desenho à mão + re- } \\
\text { cursos do computa- } \\
\text { dor; falta de portabili- } \\
\text { dade }\end{array}$ \\
\hline
\end{tabular}

Figura 1: diagrama comparativo das ferramentas elencadas. Fonte: acervo pessoal, 2013.

\section{Investigação Prática}

Em 2013 foi realizada, por este pesquisador, uma experimentação com diferentes tipos de recursos de desenho: o desenho à mão livre e com uso de quatro aparelhos; todos os quatro fazem de movimentos gestuais seu principal input. Considerando os recursos e especificidades de cada aparelho, e usando o desenho à mão como parâmetro comparativo, foi possível organizá-las na seguinte ordem: 1) o desenho à mão livre, cumprindo uma importante função de comparação para as atividades que serão desenvolvidas com os aparelhos. 2) a caneta eletrônica (Wacom Inkling), com a qual o movimento gestual é rigorosamente 
executado pelo usuário, sendo imediatamente capturado pelo sensor do aparelho, 3) a tablet gráfica (Apple iPad), aparelho em que o usuário risca e olha diretamente a tela 4) a tablet opaca (Wacom Bamboo), na qual sua caneta se comporta como um mouse mais anatômico, sendo preciso o auxílio de um computador para seu uso pleno, tornando necessário que se olhe a tela do computador, e não a tablet, ao usá-la e 5) a tela digitalizadora (Wacom Cintiq), que, conceitualmente, funciona como uma união de recursos da tablet gráfica e da tablet opaca. A experimentação consistiu no desenvolvimento do projetos de luminárias. Esta prática foi dividida em dois caminhos: no primeiro percurso foi desenvolvido um estudo preliminar de luminárias com os aparelhos usados de maneira independente e resultou nos seguintes produtos: 1, 2, 3, 4, e 5 (Ver Fig. 2).

\section{etapas de desenvolvimento}

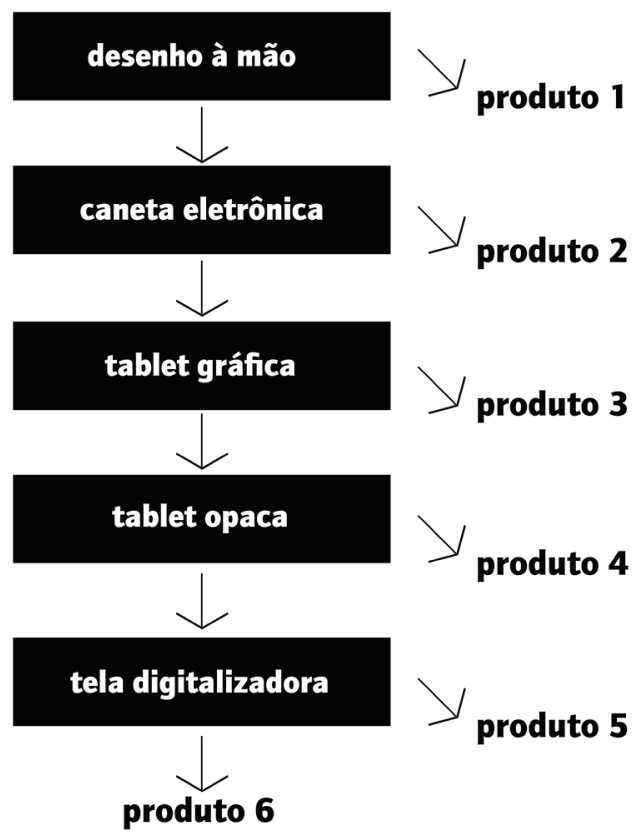

Figura 2: etapas de desenvolvimento do experimento. Fonte: acervo pessoal, 2013.

O segundo caminho envolveu o uso dos recursos: desenho à mão livre, caneta eletrônica (Wacom Inkling), tablet gráfica (iPad), tablet opaca, (Wacom Bamboo) e tela digitalizadora (Wacom Cintiq) sucessivamente, isto é, após o desenho de esboço à mão livre, deu-se prosseguimento ao projeto com os demais aparelhos, de modo que o croqui feito à mão livre teve sua continuidade gerada com o uso da caneta e assim sucessivamente até o uso do último aparelho (Wacom Cintiq). Este segundo caminho resultou no produto 6 .

\section{Análise de Resultados}

Buscou-se analisar, além do desempenho do usuário com as ferramentas, as características dos produtos gerados. No desenho à mão livre, algum tempo é necessário até que a mão se acostume aos movimentos característicos do desenhar no papel. O papel usado foi o sulfite a4, formato mais comum no mercado, e as ferramentas usadas foram lapiseiras, canetas e marcadores. Por conta da escala do papel, em combinação com os traços, cores e texturas das ferramentas, é possível rapidamente perceber que cada ferramenta oferece uma lógica de desenho diferente. Nos marcadores, por exemplo, é notável a força de suas cores, e a tinta que escorre para além da superfície de contato da ponta. Ao adequar a escala do produto a ser desenhado à espessura do traço do marcador, as imperfeições incontroláveis do traço do marcador passa a sugerir variações formais que são rapidamente apreendidas pelo desenhista e desenvolvidas no desenho subsequente. Por conta disso, é quase inevitável que se risque o mesmo desenho por diversas vezes, de modo a explorar novas formas rapidamente. A acumulação de propostas para o produto numa mesma folha permite que se absorva elas de maneira rápida e difusa, de modo que, em muitas vezes, é possível escolher uma das formas espalhadas pelo papel e desenvolver e/ou modificar suas formas. A inevitável repetição de formas aparece como reforço e compreensão da própria ideia, preparando-a para uma futura evolução. A forma final eleita não foi a última forma gerada, o que reforça o caráter de acumulação e seleção de formas do desenho à mão, conduzindo a um resultado conjunto que considera todo o processo de desenvolvimento.

A caneta eletrônica (Wacom Inkling) consiste em uma caneta esferográfica eletrônica cujos movimentos são captados por um sensor externo a ela e transformados em arquivo digital. A caneta é uma esferográfica azul comum, e nesse quesito ela funciona similarmente à experiência do desenho à mão. A grande diferença no uso desse aparelho reside no fato de que o aparelho registra em forma de animação os traços do usuário. Estando ciente disso, a experiência do desenho se torna sensivelmente diferente. Inevitavelmente, os croquis desenhados com esse aparelho saíram de maneira mais cuidadosa do que no desenho à mão, produzindo uma peça gráfica (a folha de croquis) claramente mais legível do que no primeiro processo. A noção de tempo, que no desenho à mão é completamente distorcida e variável, passa a ser notado no processo, o que a torna mais rígida. Isso faz com que inclusive os momentos de "silêncio" (sem ação) sejam registrados, de modo que a experiência do pensar desenhando seja certamente distinta da tradicional. Para além disso, a possibilidade de se assistir à produção sequencial do desenho que foi feito no papel facilita e modifica a compreensão que se tem da própria peça gráfica, tudo isso gerado de maneira instantânea pelo equipamento.

A tablete gráfica (Apple iPad) possui uma enormidade de recursos, pouco explorados e direcionados, no entanto, ao desenho projetivo. Os softwares disponiveis se resumem a emular ferramentas fisicas, como lapís, canetas e afins ou propor novos modos de gerar formas, mesmo que ainda inspirados no desenho físico. Dentre os dois casos, o segundo se mostrou ser o mais eficiente nessa plataforma por assumir, até certo ponto, suas limitações, o que resulta em uma resposta mais eficaz às questões 
técnicas do aparelho. O software Paper by 53, o mais usado durante o experimento, se enquadra nesse caso: entrega um traço suave, que responde bem à caneta. A espessura do traço varia de acordo com a sua velocidade (mais rápido, mais fino), fator que se apresenta claramente no desenho, sendo muito simples gerar formas que agradam ao olhar. No entanto, à necessidade de um nivel minimo de detalhamento da forma (proporções das linhas, por exemplo) o programa, e também as especificidades técnicas do aparellho se mostram difíceis e pouco rígidos, de controle formal reduzido, o que dificulta o estudo de um mesmo modelo em diferentes desenhos. Por outro lado, o aparelho apresenta possibilidades interessantes, como a possibilidade de recorte e ampliação das imagens produzidas ou o uso de uma rápida aquarela digital, que pode se inserir como elemento determinante no ato do projeto. A sensação de que se pode ter tudo a alguns toques de distância no iPad esbarra no pequeno espaço de trabalho e na pequena rigidez na geração de formas de seus softwares, o que significa um controle formal pequeno quando comparado às ferramentas anteriores. O iPad foi a ferramenta que desenvolveu o menor progresso no projeto da luminária.

A tablet opaca (Wacom Bamboo), após longo momento de aprendizagem, se mostrou uma ferramenta eficiente, pois oferece os recursos do computador com praticamente a mesma precisão do desenho à mão. A necessidade de se olhar à tela enquanto se desenha faz com que a execução dos traços seja pouco precisa e, num primeiro momento, pouco intuitiva, como em um desenho cego. Entretanto os recursos dos editores de imagens somados à fluidez do traço tornam dinâmica a experiência de projetar no computador, em que aumentar, repetir e distorcer formas, usar fotos de referência, sobrepor imagens tonam-se ações gestuais. 0 desempenho dos softwares de edição de imagens possibilita um pensamento rápido, análogo ao croqui, ao mesmo tempo em que agrega um rigor formal que facilita a elaboração da sequência de formas. Apesar da dificuldade inicial por conta do descolamento entre gesto e resultado do gesto, a tablete gráfica se apresenta uma ferramenta altamente precisa em seu domínio pleno.

A tela digitalizadora (Wacom Cintiq) foi a que conferiu maior sensação de liberdade de recursos de todo o experimento, reunindo qualidades da tablet opaca com da tablet gráfica. A grande tela de 24 polegadas funciona como uma tela de computador, em que o mouse e o teclado ainda funcionam como meio de interação, mas se somam à caneta eletrônica que também funciona como um mouse, que se move pela tela quando está próxima a ela ou faz um clique ao encostar nela. A familiaridade do pesquisador com os recursos dos programas de edição de imagens tornou a experiência de geração de imagens notadamente mais fluida. $\mathrm{O}$ tamanho da tela, que toma boa parte do alcance dos braços, também contribui para um livre desenvolvimento do desenho. $\mathrm{O}$ aparelho possui alguns botões customizáveis, que otimizam o uso dos recursos dos softwares ela possui, por exemplo, duas clicking wheels customizáveis que tornam seu uso uma experiência mais intuitiva. A possibilidade de se buscar imagens da internet é uma rápida maneira de inserir sugestões visuais no desenvolvimento do projeto. De maneira geral, o fato de a interface da Cintiq ser um computador pessoal, que não abdica do mouse e do teclado, torna a assimilação de seus recursos muito rápida. A diferença essencial entre a tela digitalizadora e a tablet opaca, no alcance do experimento, é que seu recurso exclusivo (o desenhar diretamente na tela do computador) é absolutamente intuitivo, ao passo em que o do outro (o desenhar em uma mesa externa ao computador) requere uma habilidade exclusiva do uso daquela ferramenta, o que com certeza requer maior tempo e dedicação para sua completa assimilação, tornando a primeira uma ferramenta mais acessível a novos usuários. Na comparação entre tela digitalizadora (Wacom Cintiq) e tablet gráfica (Apple iPad), a diferença reside essencialmente na portabilidade. A Cintiq, no modelo utilizado (com 24 polegadas) não oferece portabilidade alguma, enquanto o iPad, com o tamanho de um pequeno caderno, pode ser levado até em mãos sem maiores problemas. Ainda nesse aspecto, o iPad possui uma câmera fotográfica, o que habilita seu usuário a fazer uma exploração gráfica de um campo específico com certa qualidade. Apesar da clara superioridade de recursos e escala da Cintiq, o iPad possui a vantagem da portabilidade, o que abre um campo que a outra ferramenta não alcança.

\section{Considerações Finais}

O cenário que coloca à disposição do usuário as novas modalidades de ferramentas aqui analisadas, e ainda, que o coloca ciente dos recursos dessas ferramentas e apto a tensioná-las entre si e consigo, associando-as conforme sua vontade e necessidade, aponta para resultados positivos. Isso não eliminaria, tampouco priorizaria a importância da escolha humana no processo projetivo: deslocando-a para uma posição de confronto dinâmico entre homem e ferramenta, cada ferramenta influencia todas as outras e potencializa o desempenho do ato projetivo e da produção de imagens. Essa posição difere ligeiramente da definição de Flusser: esse tipo de ferramenta não utiliza apenas das imagens que estão contidas em si, mas também se informa usa de maneira essencial do gesto humano.

Em relação aos experimentos desenvolvidos, de maneira geral é possível perceber que nenhum dos aparelhos analisados oferece recursos que sirvam de maneira completa ao ato projetivo arquitetônico. Os aparelhos indicam uma postura no modo de geração de imagens que estabelece uma retroalimentação constante em que o usuário usa os aparelhos com seus gestos e se coloca em posição central deste processo, ainda que estando sujeito às lógicas do aparelho. O uso de cada uma dessas ferramentas, a associação ou hibridização entre elas, especialmente nas primeiras fases de elaboração formal do projeto, aponta um ganho significativo na qualidade desses processos. 


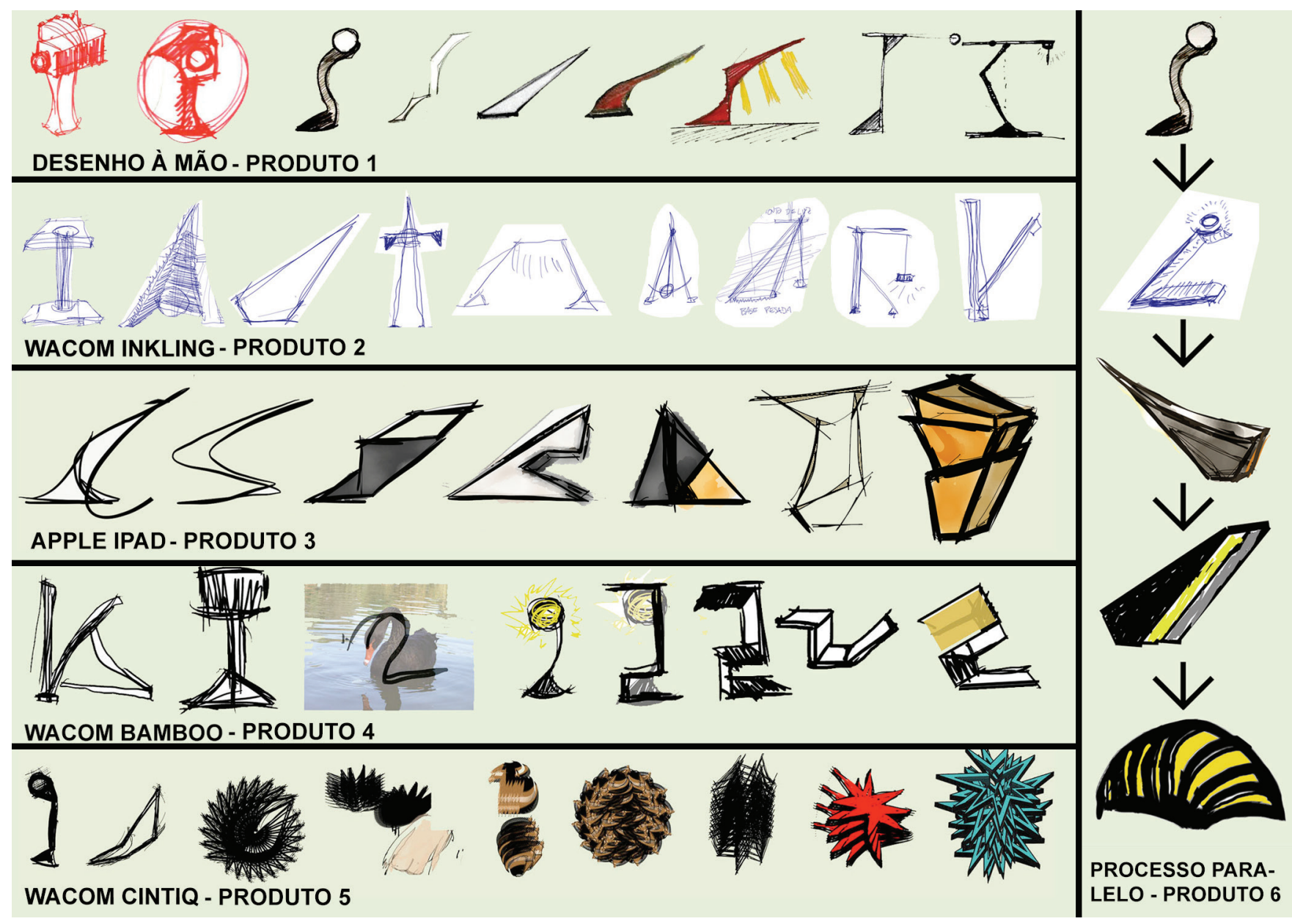

Figura 3: Imagens-síntese do processo e produtos 1, 2, 3, 4, 5 e 6. Fonte: acervo pessoal, 2013.

\section{Agradecimentos}

Ao Santander Universidades pela bolsa concedida, ao Núcleo de apoio à pesquisa em Estudos de linguagem em arquitetura e cidade - N.ELAC IAU.USP, ao Instituto de Arquitetura e Urbanismo da USP e à FAPESP pelo apoio.

\section{Referências}

Castral, P., Vizioli, S.H. T. (2011). O desenho à mão livre mediado pela tablet. Anais do Sigradi: cultura aumentada 2011 - XV Congreso de la Sociedad Iberoamericana de Gráfica Digital.

Flusser, V. (1998). O universo das imagens técnicas: elogio da superficialidade. São Paulo, Brasil: Editora Annablume.

Quantrill, M. (2002). Drawing as a gateway to computer-human integration. MIT Press Journal. 35(02), 73-78.

Veloso, P. (2011). Cultura aumentada ou substituída? Distinções entre o arquiteto-ferramenta e o arquiteto-aparelho eletrônico. Anais do Sigradi: cultura aumentada 2011 - XV Congreso de la Sociedad Iberoamericana de Gráfica Digital. 